\title{
SEX EDUCATION IN NIGERIA: ATTITUDE OF SECONDARY SCHOOL ADOLESCENTS AND THE ROLE OF PARENTS AND STAKEHOLDERS
}

\author{
*Musa, A. \\ *Department of Clinical Nursing. Sir Muhammad Sanusi Specialist Hospital (SMSSH), Kano, Kano State, Nigeria \\ *Phone: +2347065633967*Email: laamiido@gmail.com
}

\begin{abstract}
This study investigated the level of awareness of sex education among secondary school adolescents in Niger state, to assess the level of the already initiated comprehensive sex education program by the federal ministry of health. The study utilizes an empirical survey design. In order to obtain data for the research, stratified random and judgmental sampling technique were adopted. The instrument used to elicit information from the respondents was a well-structured questionnaire. Result from the study shows that it is important to impact knowledge about sex and sexuality to adolescents. As, many of the respondents show positive attitude towards sex education (65\%), they knew its effectiveness (54\%) and consequence of risk behaviors (86\%) but lacked appropriate knowledge (42\%). Based on these findings, it is therefore imperative that adolescents need more sex education at all levels with full parental participation.
\end{abstract}

Keywords: adolescents, attitude, level, Nigeria, parents, secondary school, sex education, stakeholders 


\section{BACKGROUND OF STUDY}

In a traditional Nigerian setting, children are expected to obey their parent's instruction without asking questions. It is assumed that the best way to prevent sexual immorality among youth and young adults is by keeping them almost completely if not completely ignorant of sex and sexuality matters, sometimes until their marriage night, some anxious parents might only mention one or some warning about their daughter's first menstrual experience, while for boys it is a total "blackout". In some Nigerian homes most especially in rural set up children are shy to ask questions about sexuality, and those who are brave enough to ask are often stigmatized and constantly being watched. This occurs irrespective of the fact that subject of sex and sexuality pops in the media, schools and among other groups in the society and this is a collective consciousness.

Akerele (2006) noted that "sex is something you do, and sexuality is who you are". This way of understanding sex highlights the differences between the act of sex and the individual experience of sexuality, which is an intrinsic part of who we are, one that can't be separated out of ourselves any more than our ethnicity or religious/ spiritual beliefs, sexuality is a natural and precious aspect of life, and essential and fundamental part of humanity.

In most countries of the world, young people today spend more year in school than ever in the history of humanity. Evidences also indicate that children are entering puberty earlier than decades ago, probably because of improved nutrition although other factors may also be at play. Thus, girl today have an average, their menstrual period (menarche) earlier than their mothers did and the onset of sperm development in boys is also occurring earlier than in the lives of their fathers. All those changes imply that the period from puberty to entry into marriage or the formation of a stable union has been increasing in many countries. (Kirby 2011: 1)

As the world becomes more interconnected than ever before, young people all over the world are requesting credible and accessible information on sexuality and reproduction health. They want to have their many questions and concerns about sexuality addressed. They need information not only about physiology and a better understanding of the norms that society has set for sexual behavior, but also need to acquire the skills necessary to develop health relationships and engage in responsible decision - making about sex, especially during adolescence when their emotional development accelerate. (Kirby 2011: 1)

Action Health Incorporated (AHI, 2008) observed that as children enter puberty their interest in sex increases, most of them are unprepared for the situation they face and the society, parents and school do little to clarify the situation, current norms in the society, glamorize negative sexual behaviors in the mass media and the interne but rejects young peoples natural interest in sexuality, however when the society, parents, and school does not provide the transition to adulthood with the fundamental facts of sexuality, the consequences could be disastrous for young people.

Ariba (2009) warned that since the world has become a global village, events occurring in other parts of the world that were previously remote are becoming instant influence on pattern of behaviors in other parts of. When 
these influences are negative, their impact on the recipient populations could be catastrophic, unless such populations are well informed and have evolved the appropriate behaviors to cope with such information. Through the media, the internet and direct interaction with foreigners and visitors from other countries our young population are becoming exposed to pornography, yet this population has not yet been well prepared to handle this information. This could lead to sexual health problems such as rape, incest, premarital sex, teenage pregnancies, STDs, unsafe abortions e.t.c.

In another study by AHI (2008), carried out in Lagos, Nigeria the result showed that many young people in a focus group discussion said they learned about sexuality from popular magazine such as Ikebe super star, lolly, fantasy and hints. The images prevailing in the entertainment media imply that sex in largely risk free and that everyone is doing it, which is wrong. AHI insisted that if a child is taught about what changes to expect as he grows older, he will be psychologically prepared to accept those as normal and take charge of his/her life. He will be less vulnerable to receiving wrong information that could lead to risky sexual behaviors.

In northern Nigeria girls receive sexual information from their parents before or at their menarche, which include abstinence until marriage, value of virginity, post menstrual ritual birth etc. While the boys are often separated from the girls and are often provide with bathing pants to prevent masturbation. But parents/guardians still fail to explain the aspect of sexuality and reasons for these actions (Esohe and peterinyang, 2015)

In order to respond to the needs of adolescents and young adults for information and training in behavioral skills, a growing international movement has been supporting the rights of adolescents to receive accurate and balanced information about sexuality and about how to develop healthy relationships and make decisions for themselves. This movement bases its action on internationally recognized human rights standards according to which adolescents have the right to have access to information essential for their health and development (United Nations committee on economic, social and cultural rights 2000; United Nations committee on the rights of the child, 2003). The existence of these standards implies that Government has the responsibility of developing programs that provide both adolescent girls and boys, whether in or out of school, accurate and appropriate information to enable them maintain their sexual and reproductive health. Accordingly, a growing number of reproductive health professionals, schools, clinics and nongovernmental organizations have developed and implemented a wide variety of programs aimed at providing sex education and at preventing sexually transmitted infections, including HIV/AIDs.

Typically, those programs strive to delay the initiation of sex, reduce the number of sexual encounters and sexual partners and increase the use of condoms and effective contraceptive methods among young people. Sometimes, such programs also have the goal of promoting testing for sexually transmitted infections and reducing sexual violence.

All theories of adolescent development give sexuality central prominence in negotiating the transition from child to adult. Sexuality may be used or abused; it may bring pleasure or pain, happiness or despair. The association 
between sex and adolescence has often been described as a period of storm and stress suggesting that is a tumultuous and critical stage of life (Akande and Akande, 2007)

According to United Nations report (2000), 56\% and 15\% of females within the age cohort of $15-19$ years and $20-24$ years respectively are not married out of a total of 18 million people within the age group 15 - 24 years making $19 \%$ of Nigeria's population. About one million teenagers annually get pregnant with resultant $44 \%$ births, $50 \%$ of these drop out of school and 50\% are not married.

A previous study by Ezimokhiai special program of research (2001) showed that $13 \%$ of secondary school girls, $26 \%$ of polytechnic girls, $23 \%$ of undergraduates as much as $51 \%$ of working adolescent girls have had abortion procedure before. Nine in every female adolescent would terminate their pregnancy if it occurs.

Young people need to have information on the following:

- Human sexuality: This include biological, erotic, physical, emotional, social or spiritual feelings and behaviors

- Human sexual anatomy and physiology: These include the structure and function of the internal and external sex organs.

- Sexual reproduction: This includes fertilization and conception, resulting from sexual intercourse or artificial insemination

- Sexual activity: This is the manner in which humans experience and express their sexuality. This include sexual intercourse and auto- erotism

- Reproductive health: This is the state of physical, emotional, social and psychological wellbeing in relation to sexuality

- Emotional relations: This is a non-sexual relationship or attachment between two persons

- Reproductive rights: these are the rights of individuals to decide whether to reproduce and have reproductive health information

- Sexual abstinence: This is a choice to not participate in any genital contact

- Birth Control: these are methods or devices used to prevent pregnancy

\section{STATEMENT OF PROBLEM}

Busari (2006) states that physical, psychological and social attribute of adolescence make young people particularly vulnerable to HIV and other sexually transmitted Diseases (STDs). Adolescents often are not able to comprehend fully the exposure to risk of getting pregnant, abortion or even contracting a sexually transmitted disease. Societies often compound young people's risk by making it difficult for them to learn about sex education and reproductive health. Moreover, many youths are socially inexperienced and dependent on others. When adolescents are not given or provided the necessary information about sex, they tend to get wrong information from others or wrongly timed 
information which places them at risk of teenage pregnancies, illegal abortions and STDs. Based on the above the researcher was motivated to conduct the research.

\section{OBJECTIVES OF THE STUDY}

A comprehensive sex education curricular has been endorsed by various governmental agencies and educational organizations; this study aims to investigate the attitude of secondary school adolescents towards sex education and the role of parents and stakeholders.

\section{SIGNIFICANCE OF STUDY}

The study will assess the level of success of the already initiated comprehensive sex education

\section{RESEARCH QUESTIONS}

1. What is the level of knowledge about sex education in adolescent?

2. What are the effects of sex education on adolescent?

3. What is the risk associated with sexual activity among adolescent?

4. What are adolescent attitudes toward sex education?

\section{SCOPE OF STUDY}

This study is intended to emphasize on the level of effectiveness of comprehensive sex education initiated into secondary schools in Nigeria. The research will acquire broader views of the adolescent's sexual issues, sources of sex information and valuable information about their beliefs, attitude, Perceptions, Knowledge and policies of sex education.

\section{LITERATURE REVIEW}

Sex education is a broad term used to describe the study of the characteristics of beings; a male and a female. Such characteristics make up the person's sexuality. (Burt 2011). This was further expanded by Abogunri (2005), as he echoed education as a process whereby information is given or imparted to a group of young ones and which takes into account the development, growth, the anatomy and physiology of the human reproductive system and changed that occur from youth all through the stages of adulthood. Sex education is the acquisition of knowledge that deals with human sexuality. It consists of instruction on the development of an understanding of the physical, mental, emotional, social, economic and psychological phases of human relations as they are affected by sex in other words, sex education involves providing children with knowledge and concept that will enable them make informed and responsible decisions about sexual behaviors at all stages of their lives. The aims of sex education according to British Medical association Foundations for AIDs are ambitious relating to the lifelong quality of relationships and personal 
behavior. It should be more appropriate and available to everyone through a variety of forms and informal settings. Since adolescent's behaviors predispose them to highly risky sexual activities, behavioral interventions are needed to reduce their risk of sexual behaviors. Leepson (2010) sees sex education as instruction in various physiological, psychological and sociological aspects of sexual response and reproduction.

\section{ADOLESCENT GROWTH AND DEVELOPMENT}

Spano (2007) indicated that adolescence is a time of great change for young people. It is a time when physical changes occur at an accelerated rate. The beginning of biological growth and development during adolescence is signified by the onset of puberty, which is often defined as the physical transformation of a child into an adult. A myriad of biological changes occurs during puberty including sexual maturation, increase in height and weight, completion of skeletal growth accompanied by marked increase in skeletal mass, and changes in body composition. The succession of these events during puberty is consistent among adolescents; however, there may be a great deal of deviation in the age of onset, duration and tempo of these events between and within individuals. Consequently, sexual maturation should be used to assess the extent of biological growth and development and the individual nutritional needs of adolescents in place of chronological age.

Average age of menarche is 12.4 years, menarche can occur as early as 9 or 10 years to as late as 17 years. The onset of menstruation may be delayed in females who restrict caloric intake and competitive athletes. Spermarche, or onset of sperm production occurs at approximately age 14 among males (Stang and Story, 2010).

Adolescence according Kulkarni (2008) is a period of psychosocial development beginning in preteen years, usually in conjunction with pubertal onset, and extending until the individual assumes an adult role in the society.

World health organization (2010), defines Adolescence as a period of dynamic change representing the transition from childhood to adulthood that begins at puberty, from ages $10-24$

\section{STAGES OF ADOLESCENCE DEVELOPMENT}

a. Pre - pubertal (before 10 years): This is marked by preparation for the transition. One tries to associate self with older peers and may consequently face rejection.

b. Early Adolescence (approximately 10 - 14 years): At this stage they give close friends more importance than parents; one shows occasional rudeness; experiments with self (masturbation). It is at this stage that adolescents try to explore their potentials. While some might occasionally experiment with cigarette, marijuana and alcohol.

c. Middle Adolescence (approximately 15 - 16 years): There is full self-involvement in personal affairs; worries about failure; complains that parents interfere with independence; concerned with one's appearance. One might develop some sexual and aggressive energies; shows concern about sexual attractiveness. 
d. Late Adolescence (approximately 17 - 24 years): The individual develops greater emotional stability; ability to make independent decisions; self-reliance; higher level of concern for the future; has clear sexual identity; self-regulation and self-esteem (ACT 2009).

\begin{abstract}
ADOLESCENT SEXUALITY
Aspect of children's sexuality may develop during early and middle childhood, but during adolescence their sexuality is brought into sharper focus. Sexual desires and arousal, sexual experimentation, and the formation of sexual identity are more pronounced in adolescence. These increased "feeling of arousal or desire" manifest themselves in a variety of non-coital and coital thoughts and behaviors.
\end{abstract}

\title{
SEXUAL ORIENTATION
}

Sexual orientation is an enduring pattern of romantic or sexual attraction to persons of opposite or same sex.

According to APA (2008) sexual orientation refers to an enduring pattern of emotional, romantic, and/or sexual attraction to men, women, or both sexes. Sexual orientation also refers to a person's sense of identity based on those attractions, related behaviors, and membership in a community of others who share those attractions

\section{CLASSIFICATION OF SEXUAL ORIENTATION}
a. Heterosexuality
b. Homosexuality
c. Bisexuality

\section{HETEROSEXUALITY:}

This is a romantic attraction or sexual behaviors between persons of opposite sex or gender. As a sexual orientation, heterosexuality is "an enduring pattern of emotional, romantic and/or sexual attractions" to persons of the opposite sex; it also refers to a person's sense of identity based on those attractions, related behaviors and membership in a community of others who share these attractions".

Heterosexuality is also referred to as Sexual intercourse which is also known as coitus or copulation. Miller (2006) noted that sexual intercourse is the behavior used most often to report the status of adolescent's sexual behavior. The latest figures show that more than one half of high school seniors $(61.9 \%)$ have had coitus at least once. Approximately $7.8 \%$ of young adolescents had sex prior to age 13 .

\section{FORMS OF COITUS}

i. Oral sex: Also known as fellatio (peno - oral), Cunnilingus (Oro - Vaginal), and Oro - anal (rimming)

ii. Introital Penetration: Also known as Vaginal Sex 


\section{iii. Digital sex: Also known as fingering}

iv. Anal sex

v. Fisting: This is where the fist is used to penetrate the introitus or the Anus.

Some forms of coitus such as anal sex, fisting and rimming are very dangerous even when done with the right person, variables such as early maturation, substance use, having a history of sexual abuse, and having friends who view illicit sexual behaviors as acceptable are linked to the in appropriate or pre-marital initiation of sexual intercourse. Having educational plans, good grades, high religiosity, family support, and parental supervision and advice are linked to the delay of sexual intercourse.

\section{HOMOSEXUALITY}

This is romantic attraction or sexual behaviors between members of same sex or gender. As a sexual orientation homosexuality is "an enduring pattern of emotional, romantic, and/or sexual attractions" primarily or exclusively to people of same sex. It "also refers to a person's sense of identity based on those attractions, related behaviors and membership in a community of others who share those attractions" the most common terms used for homosexuals are lesbian and gay for females and males respectively.

Since the end of $19^{\text {th }}$ century, there has been global movement towards increased visibility and legal rights for homosexuals, including the rights to marriage and civil unions, adoption and parenting, employment, military service, equal access to health care, and the introduction of anti-bullying legislation to protect gay minors. Though gay marriage has been legalized in many countries (e.g. USA, having more than 30 million homosexuals) it is still considered a taboo in many cultures and religions. Health-wise, homosexuals are at high risk of rectal prolapsed, rectal cancer and STIs (e.g. HIV and HPV). Anal sex is sometimes referred to as "painful sex" because the anus does not secrete lubricants and is less elastic which might lead to injury. Though psychologist agrees that homosexuality is a normal sexual orientation, it is opposing to human nature as the rectum is not physiologically a penile or dildo receptacle. (APA, 2008)

\section{BISEXUALITY}

This is a romantic attraction, sexual attraction or sexual behaviors toward both males and females, or romantic or sexual attraction to people of any sex or gender identity. The American psychological Association states that "Sexual orientation falls along a continuum. In other words, someone does not have to be exclusively homosexuals or heterosexuals but feels varying degrees of both. (APA, 2008). 


\section{HUMAN SEXUAL ACTIVITY}

It is also known as human sexual practice or human sexual behavior is a manner in which humans experience and express their sexuality. People engage in a variety of sexual acts from time to time, for a wide variety of reasons.

\section{TYPES OF SEXUAL ACTIVITIES}
a. Autoerotism (Masturbation)
b. Alternate or conventional behaviors (e.g. fetishism, paraphilia, and zoophilia)

\section{AUTOEROTISM (MASTURBATION)}

When surveyed, $80 \%$ men and $60 \%$ women report masturbating or bringing themselves to orgasm by age 18 . Adolescent males masturbate 2-3 times as often as females, and it is usually their earliest sexual experience.

However, masturbation is still considered "taboo" in many countries especially in African countries and forbidden by some religions. It appears that parents rarely talk to adolescents about masturbation and it is perceived by many adolescents as normal and right.

\section{TYPES OF MASTURBATION}

i. Solo masturbation

ii. Mutual masturbation

Solo Masturbation: This involves self-stimulation by touching, pressing, rubbing or massaging a person's genital area, either with the fingers or against an object such as a pillow; inserting fingers or an object into the vagina or anus. It may also involve touching, rubbing, or pinching the nipples or other erogenous zones while masturbating. Both sexes sometimes apply lubricating substances to intensify sensation. Reading or viewing pornography, sexual fantasy or other erotic stimuli may also lead to a desire for sexual realities such as by masturbation. Most surveys show that this is the first stage of sexual activity in adolescent as many learn it themselves while bathing or from peers. Some may go to extend of using sex toys for both male and female.

Sex toys are objects or devices that are primarily used to facilitate human sexual pleasure. Many popular sex toys are designed to resemble human genitals and may be vibrating or non-vibrating this may include: erotic electrostimulation devices (Estim), Erotic furniture, General penetrative devices (GPD), Vibrators, Nipple toys and penile toys.

Most adolescents become exposed to these devices from the media or friends and do not have appropriate knowledge of these devices, most of which are very harmful, dangerous and life threatening. Meanwhile many 
countries consider sex toys illegal e.g. India, South Africa, Malaysia, and all Islamic nations. It is also forbidden by some religions e.g. Islam, Christianity, and Sikhism, but Nigeria happens to be silent about its legal status.

Mutual Masturbation: This form of masturbation is done by two more or persons, it is considered by some as foreplay while some adolescents use this method as a form of first sexual experience and to avoid pregnancy.

\section{NEGATIVE EFFECTS OF MASTURBATION}

i. Lowers sperm count

ii. Masturbation causes weakness,

iii. May cause erectile dysfunction

iv. Addiction

v. Social stigma

vi. Creates drowsiness

vii. Sensory impairment

viii. Transmission of infections (STDs, PIDs, and UTIs) Via sex toys

ix. Death, burn, cardiac arrest and tissue damage caused by estim devices and other electrical devices

x. Traumatic Lacerations caused by glass sex toys and heavy weight devices. (Wilson, 2014)

Adolescents should be well informed about both the positive and negative effects of masturbation as many institutional curricular give more concentration to the positive effects negating its negative effects.

\section{ALTERNATE OR CONVENTIONAL BEHAVIORS:}

This include Sexual Fetishism and Zoophilia:

a. Sexual fetishism: This is a sexual focus on non-living object or non-genital body parts. A sexual fetish may be regarded as a non - pathological aid to sexual excitement or as a mental disorder if it causes significant psychosocial distress for the person or has detrimental effects on important areas of their life. Fetishes include clothing (58.3\%), rubber and rubber items (22.9\%), footwear (14.6\%). body parts $(14.6 \%)$, leather $(10.4 \%)$ and soft materials or fabrics $(6.3 \%)$. Majority of fetishes are male.

b. Zoophilia: is a paraphilia involving a sexual fixation on animals. Bestality is cross species sexual activities between human and non - human animals. Sex with animal is not outlawed in some countries (e.g. Sweden and Belgium) but in most countries it is outlawed under animal abuse laws. People with zoophiliac sexual activities are known as "zoophiles" or zoophiles. Infections that are transmitted from 
animals to humans via cross sexual activities are called zooneses e.g. Brucellosis, Q - fever, leptospirosis and toxocariasis. Allergic reaction to animal semen may occur, bites and other trauma from penetration or trampling may occur. Zoophilia is now being widely depicted in pornography exposing adolescents to learning and imitating the act especially those who lie with animals or keep them as pets. (In. Maibasira, A.M 2015).

\section{SUBSTANTIAL SEXUAL BEHAVIOR}

One may change his sexual orientation and activity as a result of environmental change which permits, encourage, or compels the behavior. An example of situational sexual activity may be when people might not have sex with prostitutes in their community because of religious restrictions but may do it somewhere else. A situation where a heterosexual becomes a homosexual in prison, in boys-only and girls-only boarding schools, or in military camp. Environmental change is a very important factor in adolescents' sexual behavior with lack of adaptation.

\section{TYPES OF SEX EDUCATION}
a. Abstinence centered Education
b. Abstinence plus Education
c. Comprehensive sex Education
d. Lesbian, Gay, Transgender and Bisexual sex Education.

a. ABSTINENCE CENTERED EDUCATION: Also known as abstinence - only - until marriage or sexual risk avoidance programs, a strictly endorsed abstinence; teaches that abstinence is the only accepted behavior; limits sex contents; usually omits controversial topics such as abortion, masturbation and sexual orientation; strictly oppose abortion but may support adoption instead. In this form of sex education abstinence is the only accepted behavior. (Alford 2008).

b. ABSTINENCE PLUS EDUCATION: This program is quite similar to abstinence centered education but in addition it explores the context and meanings involved in sex. It discusses on STDs, contraception, and acknowledges that adolescents are sexually active but promotes strict abstinence and frowns on all forms of pre - marital and extra - marital sexual activities.

c. COMPREHENSIVE SEX EDUCATION: Teaches abstinence but also encourages use of condoms for risk reduction in case of extramarital and premarital sexual activities; it helps young people explore their own values, goals and options; includes accurate and factual information on abortions, masturbation, and sexual 
orientation; teaches that women with unintended pregnancies have a choice of either raising the baby or safe abortion. (Collins 2009).

d. LESBIAN, GAY, TRANSGENDER AND BISEXUAL SEX EDUCATION (LGTB SEX EDUCATION): This type of seX education is the most controversial type of sex education centered on teaching young adults in high schools on the reality of lesbian, gay, transgender and bisexual activities, expressing them as a rather normal sexual orientation. It is also aimed at reducing the rate of discrimination against LGTBs. It is endorsed by USA, Belgium, and Sweden.

\section{IMPORTANCE OF SEX EDUCATION FOR ADOLESCENT}

International Planned Parenthood foundation (2008) noted that youngsters usually derive information on sex and from friends, books, media adverts, television, magazines and the internet. The problem is that these sources may or may not really provide them with correct information. As such, sex education will help in transferring authentic information and in the process also correct any misinformation that they may have apart from adding to their already existing knowledge.

- Sex education imparted through schools can prove to be a significant and effective method of bettering the youngster's sex - related knowledge, attitude and behavior

- Sex education in school is important because many parents are shy about talking/teaching their children on this subject

- Educating children on sex related issues also require one to know how to approach the subject, what information to impact and what to hold back. All these can be carefully handled by a trained sex educator

- It is a fact that more and more teens these days are engaging into premarital sex. This will help them make better informed decisions about their personal sexual activities

- Sex education reduces sexual risk e.g. Rape, STDs, injury and death from mal use of sex toys etc.

- It reduces indecency in the society.

\section{THE ROLE OF PARENTS}

According to Kim and Ward (2007), Parents have a unique position when it comes to sex education because parents are the earliest socialization agents in children's lives. Many parents actually want to teach and talk to their children about sex but they often doubt their skills and competency and are often shy to impart the knowledge. It is important to note that though parents can influence their children's beliefs and attitudes about sex more, they may not necessarily pass down specific message related to sex. There are certain positive benefits of parents opening up communication with their children about sex. There are indirect effects on the sexual health of adolescents, such as prompting them 
to have more open talks with their partners and increasing their knowledge of STDs and even reduce the chances of risky behaviors.

Afifi (2008), Stressed that parents are generally also shy and embarrassed to talk about such a topic. Parents are also unsure about the right timing to approach their children with such discussions and they fear that they may not have adequate knowledge and thus misinform their children. When parents do profess to be open about sex communication, they are reactive rather than proactive, meaning that they will only talk about it when the issue arise or when their children approach them with questions. Paradoxically adolescents desire more sex communication with their parent. Research also covered that interestingly, religious parents and adolescents were more comfortable talking about sex than the non-religious families. It is therefore necessary for parents to vive proper sex education to their wards.

\section{RELIGIOUS VIEWS ON SEX EDUCATION}

There are different and diverse views about sex and sexuality education, but this research will review literatures related to the most widely accepted Islamic and Christian views on the subject matter

\section{ISLAMIC VIEW ON SEX EDUCATION}

Those who think sex education is not allowed in Islam are completely wrong. The books of Islamic jurisprudence expose several topics promoting sexual awareness, including discussion of menstruation, pregnancy, rules of sexual intercourse, rules of marriage, ritual birth, and punishments for committing adultery or fornication among others.

Islam encourages sex education as at the time of the noble prophet Muhammad (S. A.W.), men and women are never shy to ask the prophet about all affairs of their sexual life.

According to Tirmidhi; Aisha the wife of the prophet testified by saying "Blessed are the women of the Ansar. Shyness never stands their way to seeking knowledge about their religion”. Meanwhile shyness is a part of Islamic faith, but the prophet said that there is no shyness in the matters of religion.

In Islam it is a firm belief that facts about sex should be taught to children in a way that commensurate with their age as they grow up both by the family and Islamic school under the principles of Islam regarding sex and sexuality. It is emphasized that this should be done within the total context of Islamic teachings, so that the youth beside them getting the correct physiological knowledge become fully aware on the sanctity of sexual relation in Islam and the grave sin and punishment of blemishing such sanctity. Islam doesn't agree or support to any degree the comprehensive sex education but agrees with abstinence plus education under Islamic jurisprudence. (Mawlawi, 2014)

\section{CHRISTIAN VIEW ON SEX EDUCATION}

Due to the intrinsic complexities of human sexuality, the physical aspects cannot be separated from moral responsibility. In Christianity sexuality is considered a gift to mankind from God. So it must be morally followed, it 
is advised that sex education should purposely be given at home by parents and that abstinence plus education is the only accepted form according to some Christian sources (esp. catholic). Comprehensive sex education is completely detested as it presents perversion, fornication, homosexuality and living together as "normal" all of which is contrary to the scriptures. Parents should be actively involved in child upbringing and that includes instructions on sexuality. Parents are advised to begin sex talk when children are very young, speaking matter of facts, with preschoolers about their bodies and how men and women are made differently. Before parents allow a school system to instruct their wards in sexuality or morality, they must be sure their children have already learned the truth. (Got Questions Ministries, 2015).

\section{CONSEQUENCE OF SEXUAL ACTIVITY IN ADOLESENTS}

In Nigeria, problems associated with adolescent's sexual health include high rate of teenage pregnancy a rising incidence of sexually transmitted disease, high rates of abortion mortality e.t.c. medical problems associated with adolescent's '5sexual behaviors are a major health burden too Nigerians. Problems are not confined to pregnancy but include secondary infertility and development of cervical abnormalities in adolescents. Adolescents who became sexually active enter an arena of high-risk behavior that leads to physical and emotional damage. Each year, influenced by the combination of a youthful assumption of invincibility, and a lack of guidance (or misguidance and misleading information) millions of adolescents ignore those risks and suffer the consequences. Young men who have sex with men are at high risk of getting HIV and other sexually transmitted diseases. It has been found that individuals infected with STDs are at least two to five time more likely than uninfected individuals to acquire HIV if exposed to the virus through sexual contact. One study found that among gay male clinic patient screened for STDs, those $15-20$ years old had the highest age specific rates of rectal Chlamydia and gonorrhea. These findings suggest the need for effective sex education for adolescents.

\section{METHODOLOGY \\ RESEARCH DESIGN}

The design for this study is a descriptive and investigative method that explores the attitude of secondary school adolescents towards sex education in Niger state and the role of parents and stakeholders.

\section{SETTING}

The study was conducted in Niger state. The state has over 250 Secondary schools and a number of vocational training center where adolescents attend for skill acquisition. 


\section{TARGET POPULATIONS}

The population of study consists of one hundred subjects $(\mathrm{n}=100)$ from three (3) public secondary schools and two (2) Private schools, between the age ranges of $10-24$ years.

\section{SAMPLE AND SAMPING TECHNIQUE}

A total of one hundred $(n=100)$ samples were randomly selected from three (3) public schools and two (2) private schools in three local government areas. Twenty samples were randomly selected from each school in order to obtain participants for the study, Stratified Random or probable sampling and Judgmental non random sampling technique were used. The secondary schools were stratified into three groups, which include senior and junior secondary schools, Boys and Girls, and Public and private secondary schools, where one hundred (100) respondents were randomly selected. Judgmental sampling was used to select five Secondary schools within Niger state.

\section{INSTRUMENT FOR DATA COLLECTON}

The instrument used is a well-structured questionnaire designed by the researcher to elicit the response from the respondents. The questionnaire is made up of six (6) sections with six (6) items each.

\section{VALIDITY/RELIABLITY OF THE INSTRUMENT}

In order to ensure the validity of the instrument, a pilot study was carried out using twenty (20) students. The instrument measures responses of the respondents with each question related to the topic of investigation. The psychometric properties of the instrument make it valid, stable, and reliable.

\section{METHOD OF DATA COLLECTION}

Once an official permission was obtained from various schools, the researcher took the questionnaire to each school which was administered to the students in JSS 3 - SSS 3. The respondents were approached and informed about the purpose of the study before being asked to participate, the voluntary nature of their participation was emphasized and steps to ensure confidentiality and anonymity were detailed. Participant's consent was assured by their willingness to complete and return the questionnaires. Data was collected from $3^{\text {rd }}$ to $27^{\text {th }}$ of June of 2017 and the respondents took a mean time of 56minutes $(x=56)$ and an average of 20minutes to respond completely and was immediately retrieved. No compensation was provided to the respondents.

\section{ETHICAL CONSIDERATION}

The researcher began by seeking the permission from authorities of each school and fully explained the purpose and goals of the study before taking the questionnaires for distribution. All information obtained from the respondents was 
treated as confidential to avoid identification They were made to respond to the questionnaire freely and voluntarily without being mandated to do so. Privacy, anonymous and confidentiality was ensured.

\section{METHOD OF DATA ANALYSIS}

Raw data was collected which was analyzed using Multivariate Descriptive statistics. The nominal and ordinal measurement scales were ascertained; graphical representations (bar charts, pie charts, measurement model, and scatter plot) were adopted. Measurements such as Central tendencies, Standard deviations were used for the analysis. And tables such as variable tables and contingency tables were also used to provide easy and quick interpretation.

\section{DATA ANALYSIS}

SECTION A: Demographic Data

Table I: Showing the age distribution of the Respondents

\begin{tabular}{llll}
\hline Age $(\mathrm{x})$ & Frequency $(\mathrm{f})$ & Percentage $(\%)$ & Cumulative frequency \\
\hline $10-14$ & 10 & 10 & 10 \\
$15-16$ & 54 & 54 & 64 \\
$17-24$ & 36 & 36 & 100 \\
Total & $£ f=100$ & $£ \%=100$ & \\
\hline
\end{tabular}

Table II: Showing the sex distribution of the Respondents

\begin{tabular}{llll}
\hline Gender $(\mathrm{x})$ & Frequency (f) & Percentage $(\%)$ & Cumulative frequency \\
\hline Male & 40 & 40 & 40 \\
Female & 60 & 60 & 100 \\
Total & $£ f=100$ & $£ \%=100$ & \\
\hline
\end{tabular}

Table III: Showing the distribution of the respondents by religion

\begin{tabular}{llll}
\hline Religion (x) & Frequency (f) & Percentage (\%) & Cumulative frequency \\
\hline Islam & 90 & 90 & 90 \\
Christianity & 10 & 10 & 100 \\
Atheism & 0 & 0 & 100 \\
Total & $£ f=100$ & $£ \%=100$ & \\
\hline
\end{tabular}


Table IV: Showing the distribution of the respondents by marital status

\begin{tabular}{llll}
\hline Marital status (x) & Frequency (f) & Percentage (\%) & Cumulative frequency \\
\hline Single & 74 & 74 & 74 \\
Married & 6 & 6 & 80 \\
Divorced & 0 & 0 & 80 \\
In a relationship & 20 & 20 & 100 \\
Total & $£ f=100$ & $£ \%=100$ & \\
\hline
\end{tabular}

Table V: Showing distribution of the respondents by school type

\begin{tabular}{llll}
\hline School type (x) & Frequency (f) & Percentage (\%) & Cumulative frequency \\
\hline Public & 40 & 40 & 40 \\
Private & 60 & 60 & 100 \\
Total & $£ f=100$ & $£ \%=100$ & \\
\hline
\end{tabular}

Table VI. Showing distribution of respondents by their class in School

\begin{tabular}{llll}
\hline Class $(\mathrm{x})$ & Frequency $(\mathrm{f})$ & Percentage $(\%)$ & Cumulative frequency \\
\hline JSS 3 & 25 & 25 & 25 \\
SSS 1 & 37 & 37 & 62 \\
SSS 2 & 31 & 31 & 93 \\
SSS 3 & 7 & 7 & 100 \\
Total & $\mathfrak{f f}=100$ & $£ \%=100$ & \\
\hline
\end{tabular}

Table VII: Showing distribution of the respondents by those they reside with

\begin{tabular}{llll}
\hline Guidance $(\mathrm{x})$ & Frequency $(\mathrm{f})$ & Percentage $(\%)$ & Cumulative frequency \\
\hline Alone & 8 & 8 & 8 \\
Father only & 6 & 6 & 14 \\
Mother only & 5 & 5 & 19 \\
Both parents & 75 & 75 & 94 \\
Step - parents & 2 & 2 & 96 \\
Others: Husband & 2 & 2 & 98 \\
$\quad$ Wife & 2 & 2 & 100 \\
Total & $£ f=100$ & $£ \%=100$ & \\
\hline
\end{tabular}




\section{GENERAL INFORMATION (G.I. VI)}

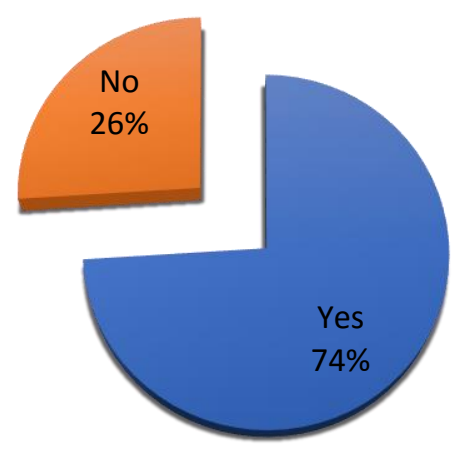

Figure I: Have you ever heard of sex education?

According to the chart above $74 \%$ of the respondents have heard of sex education while $26 \%$ have not heard of sex education.

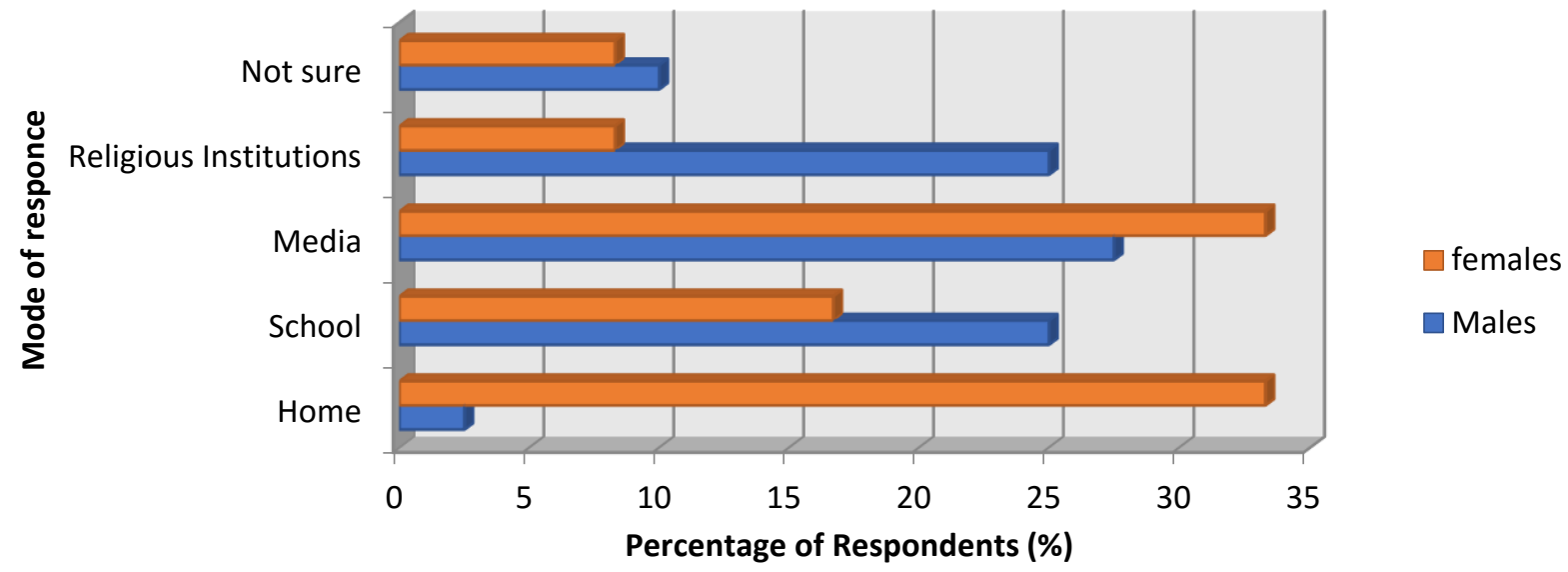

Figure 4.1.1: Showing Respondent's First source of sex education

From the Chart Above, 12.5\% of Male respondents had their first sex information from home, 25\% from school. $27.5 \%$ from the media. $25 \%$ from religious institutions, while $10 \%$ are not sure, however $33.3 \%$ of females had their first information from home, $16.7 \%$ from school $33.3 \%$ from the media. $8.3 \%$ from religious institutions while $8.3 \%$ are not sure. 


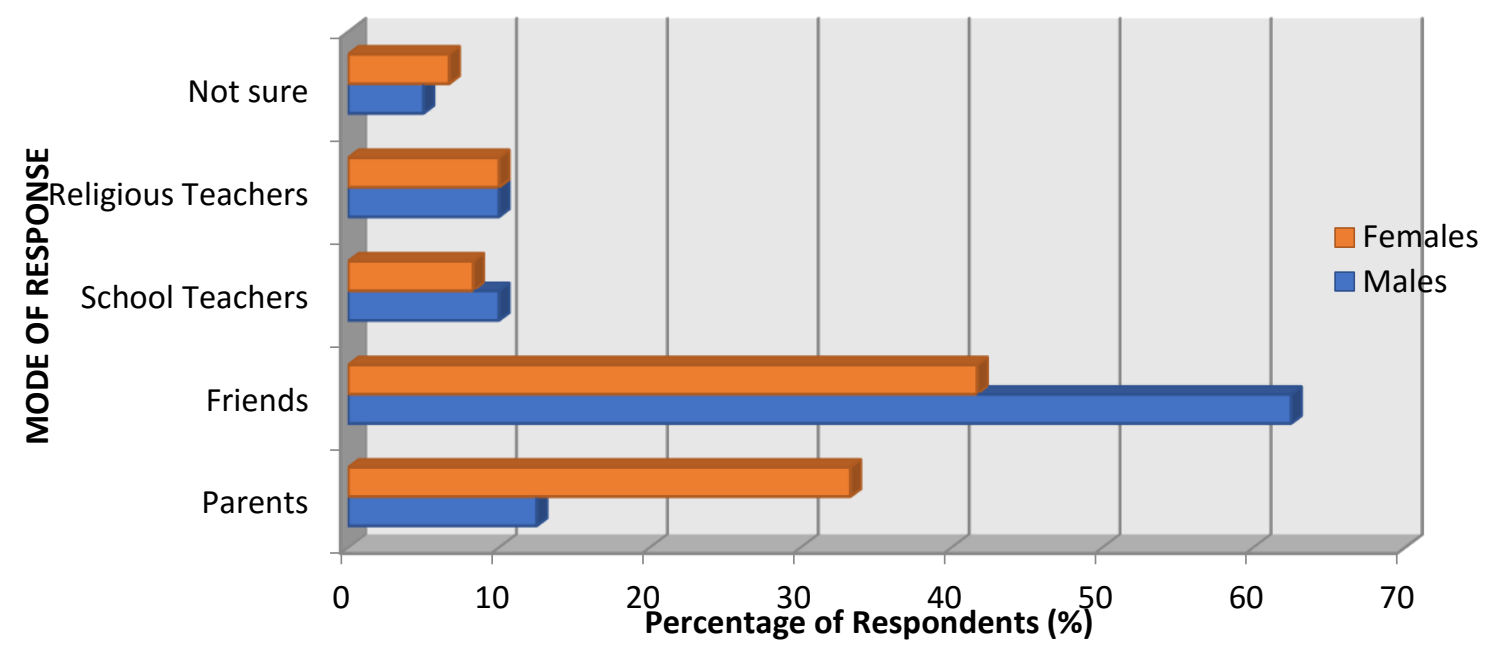

Figure II: Showing the Respondents first sex educator

The Chart shows that $12.5 \%$ of the respondent got their information from their parents, $62.5 \%$ from friends $10 \%$ from school teachers, $10 \%$ from Religious teachers, and 5\% are not sure who their first educator was. It also exposes that $33.3 \%$ of females agreed that their parents were their first sex educators, $41,7 \%$ from their friends, $8.3 \%$ from their school teachers, $10 \%$ from their religious teachers while $6.7 \%$ are not sure 


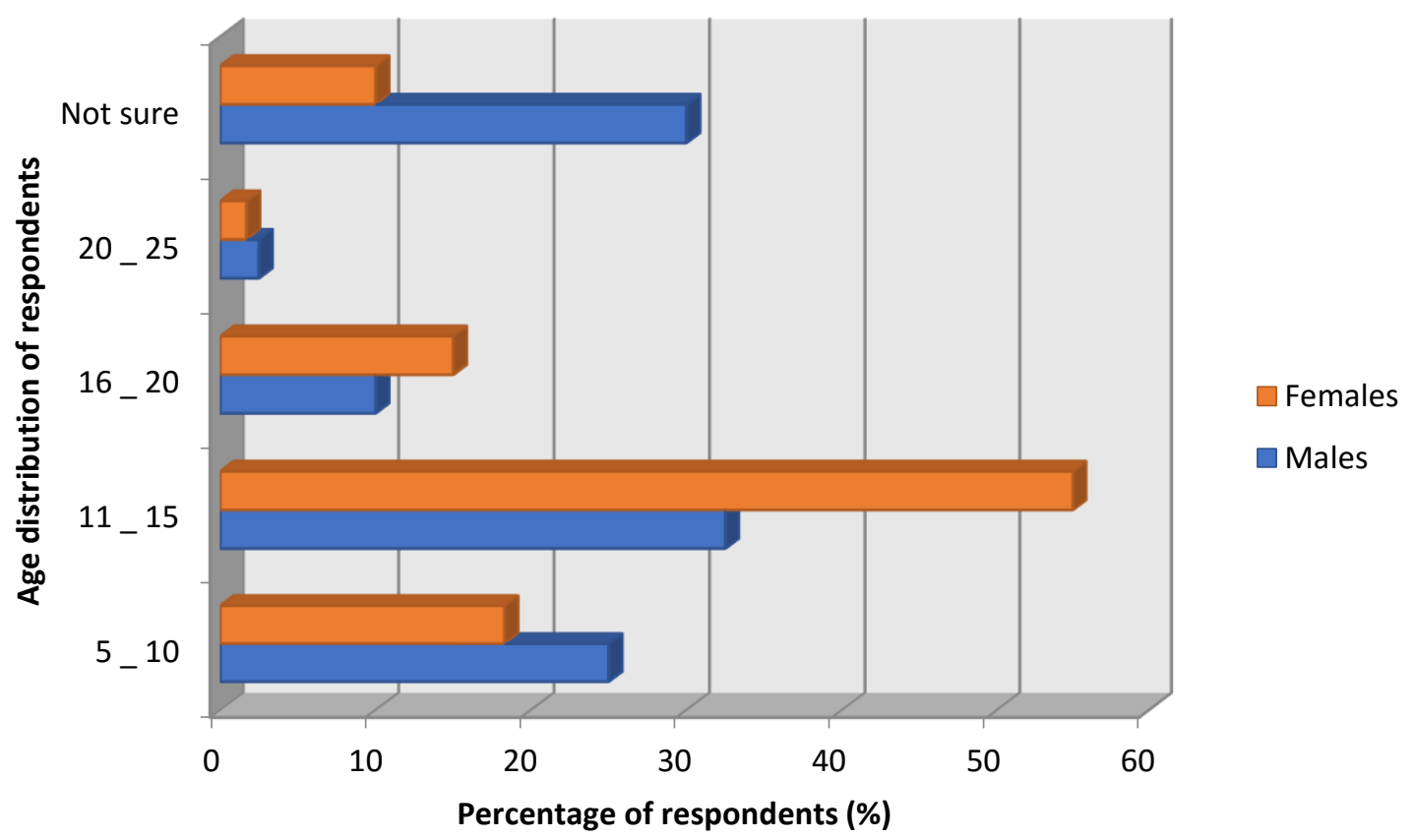

Figure 3: Showing the age of the respondents when they first had

Majority of the male respondents (32.5\%) got their first sex information at the age of $11-15$ years, $30 \%$ are not sure, $25 \%$ around $5-10$ years, $10 \%$ around $16-20$ years, $2.5 \%$ around $20-25$ years. While majority of the female respondents 55\% also got their first sex education around the age of $11-15$ years, $18.3 \%$ around $5-10$ years, $15 \%$ around $16-20$ years, $1.7 \%$ around $20-25$ years and $10 \%$ are not sure. 


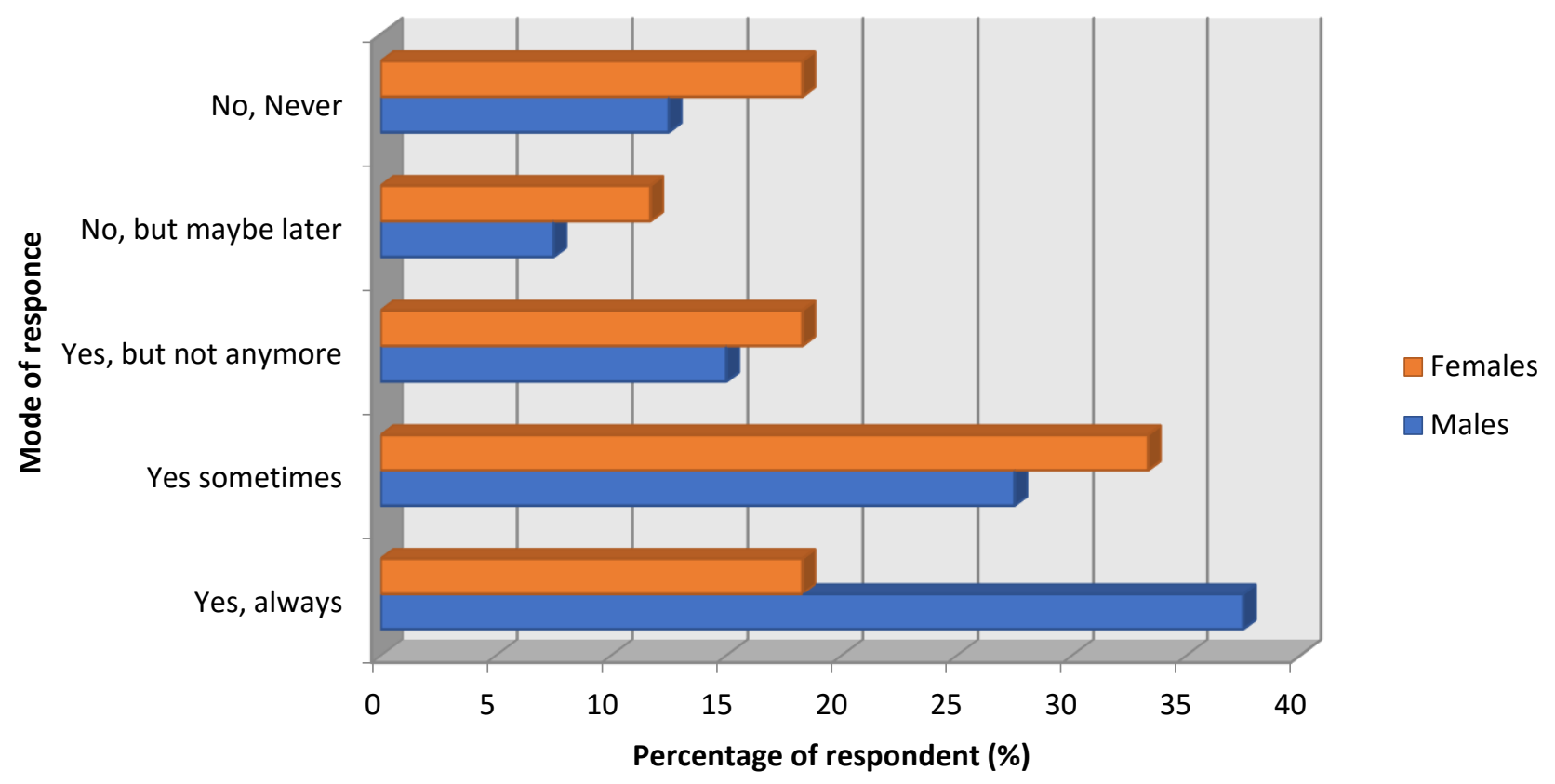

Figure 4. Showing the level of viewing pornography amongst respondent

From the above chart and table $37.5 \%$ of male respondents always view pornography and sexual magazines, $27.5 \%$ view occasionally, $15 \%$ have stopped viewing, $7.5 \%$ have the tendency of viewing later and $12.5 \%$ have never viewed pornographic materials. While $18.3 \%$ of female respondents always view pornography and sexual journal, $11.7 \%$ have the tendency of viewing later, while $18.39 \%$ have never viewed pornographic materials before. 

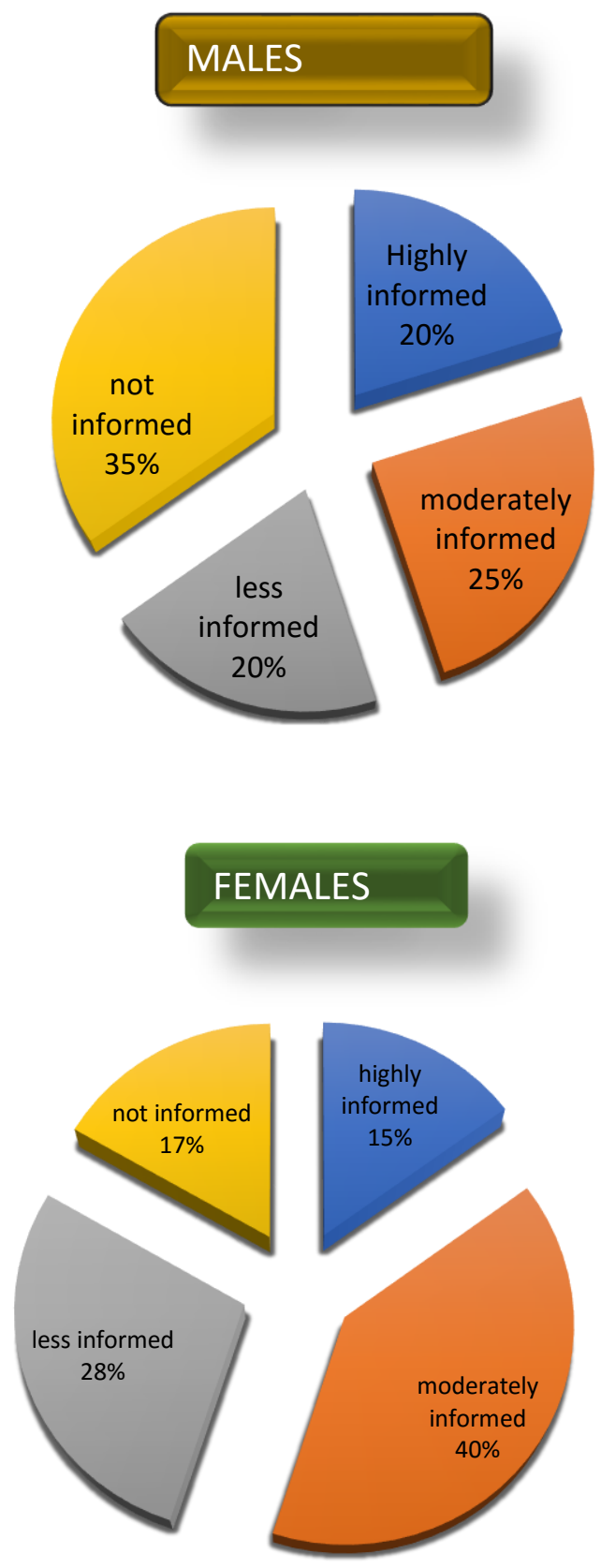

Figure 5. Showing a measurement model on respondents perceptional rating of their level of sex and sexuality information 
The Measurement model above shows that, female respondents (55\%) are more informed on sex and sexuality than male respondents (45\%), per their perceptional rating. Giving a high percentage of males that perceive themselves as less (20\%) or not $(35 \%)$ informed at all.

Table VIII: Showing the comparison of the perceptional rating between respondents of public and private schools

\begin{tabular}{lllll}
\hline Mode of response & \multicolumn{2}{l}{ Public schools } & \multicolumn{2}{l}{ Private schools } \\
\hline \multirow{2}{*}{ Highly Informed } & F & $\%$ & F & $\%$ \\
\cline { 2 - 5 } Moderately informed & 10 & 16.7 & 20 & 50 \\
Less informed & 7 & 11.7 & 9 & 22.5 \\
Not informed & 23 & 38.3 & 6 & 15 \\
& 20 & 33.3 & 5 & 12.5 \\
& $£=60$ & $£ \%=100$ & $£ f=40$ & $£ \%=100$ \\
\hline
\end{tabular}

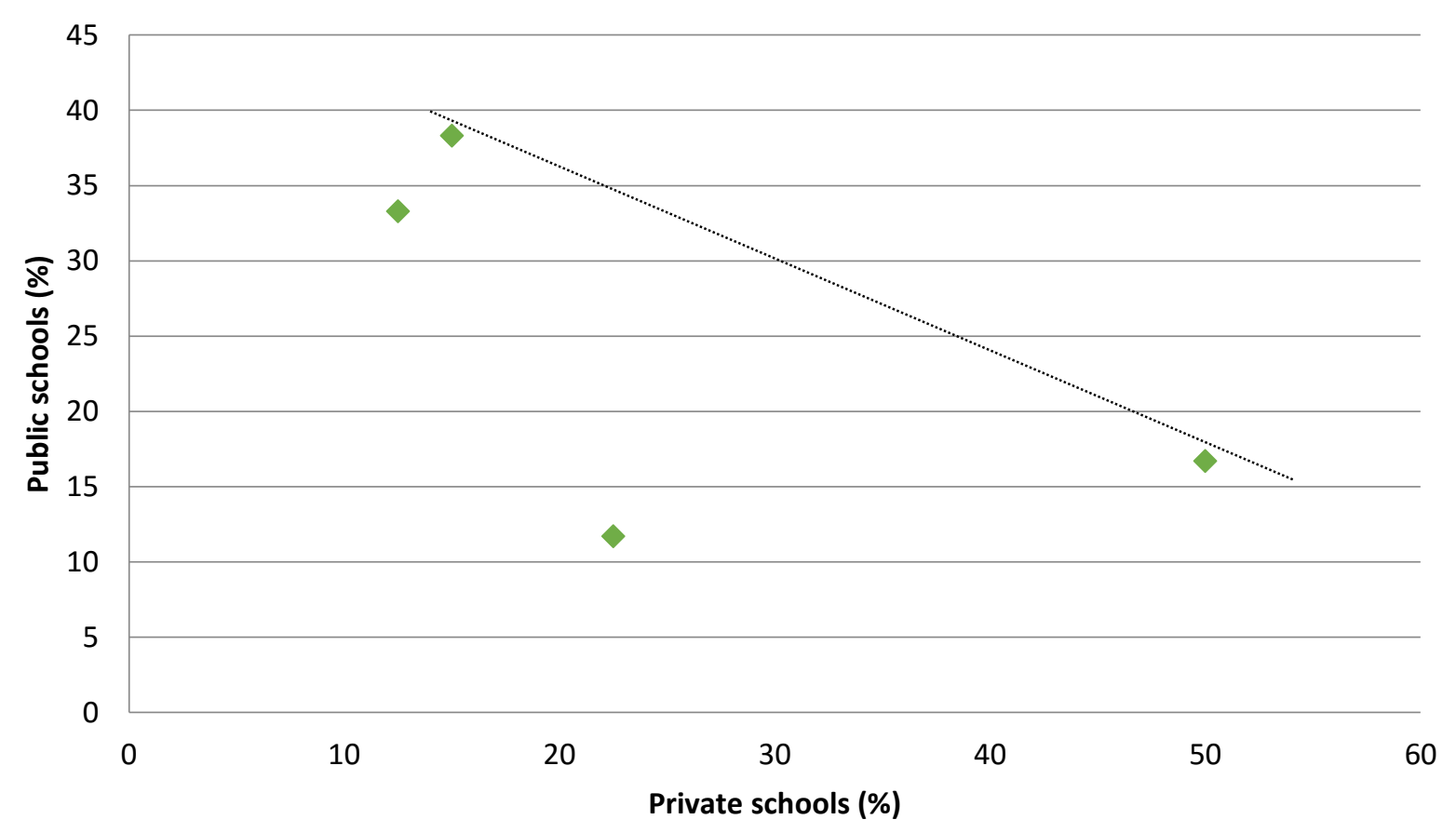

Figure 6: A scatter plot showing the correlation of the perceptional rating between public and private school respondents.

The contingency table above shows that $16.7 \%$ of respondents from public schools think they are highly informed, $11.7 \%$ think they are moderately informed, $38.3 \%$ thinks they are less informed and $33.3 \%$ thinks they are less 
informed. Compared to $50 \%$ of respondents from private schools that think they are highly informed, $22.5 \%$ think they are moderately informed, $15 \%$ thinks they are less informed and $12.5 \%$ are not informed. The scatter plot shows a strong negative correlation between the two variables which shows no positive relations between the variables

Research Question 1: What is the level of knowledge of adolescents on sex and sexuality?

Table IX: Knowledge of respondents on sex and sexuality

\begin{tabular}{llllll}
\hline S/N & Statement & $\begin{array}{l}\text { Strongly } \\
\text { agree }(\%)\end{array}$ & $\begin{array}{l}\text { Agree } \\
(\%)\end{array}$ & $\begin{array}{l}\text { Disagree } \\
(\%)\end{array}$ & $\begin{array}{l}\text { Strongly } \\
\text { Disagree (\%) }\end{array}$ \\
\hline 1 & Masturbation is very healthy & 28 & 24 & 27 & 21 \\
2 & Sexual abstinence is important for unmarried adolescents & 54 & 27 & 8 & 31 \\
3 & Condom use for protection is better when not married & 11 & 35 & 25 & 29 \\
4 & Anal sex and homosexual activities are very dangerous & 56 & 16 & 9 & 19 \\
5 & Abortion is the best way for getting rid of unwanted pregnancy & 13 & 27 & 26 & 34 \\
6 & Sex toys are dangerous & 23 & 33 & 15 & 29 \\
\hline
\end{tabular}

From the above table (52\%) were on the opinion that masturbation is very healthy; and that sexual abstinence is important for unmarried adolescents (81\%) but condom use for protection is better for unmarried adolescents (46\%); that anal sex and homosexual activities are very dangerous (72\%) and that abortion is the best solution for getting rid of unwanted pregnancy (40\%); that sex toys are dangerous (56\%). This shows that some of the respondents' lack knowledge about sex and sexuality.

Research Question 2: What is the attitude of adolescents towards sex education?

Table X: Showing the attitude of adolescents towards sex education

\begin{tabular}{|c|c|c|c|c|c|}
\hline $\mathrm{S} / \mathrm{N}$ & Statement & $\begin{array}{l}\text { Strongly agree } \\
(\%)\end{array}$ & $\begin{array}{l}\text { Agree } \\
(\%)\end{array}$ & $\begin{array}{l}\text { Disagree } \\
(\%)\end{array}$ & $\begin{array}{l}\text { Strongly } \\
\text { Disagree } \\
(\%)\end{array}$ \\
\hline 1 & I find classes of sex education interesting & 29 & 48 & 15 & 8 \\
\hline 2 & $\begin{array}{l}\text { Sex education has helped me to understand and deal with my sexual } \\
\text { urge }\end{array}$ & 44 & 41 & 14 & 1 \\
\hline 3 & $\begin{array}{l}\text { Sex education is the best way to educate adolescents on illicit sex and } \\
\text { its consequences }\end{array}$ & 45 & 38 & 10 & 7 \\
\hline 4 & I feel shy to discuss about sex education & 30 & 35 & 32 & 3 \\
\hline 5 & Sex education is a taboo & 10 & 27 & 32 & 31 \\
\hline 6 & I educate others positively about sex & 30 & 21 & 20 & 29 \\
\hline
\end{tabular}


From the table above, majority of the respondents find classes of sex education interesting (77\%). And that it has helped them understand and deal with their sexual urge (85\%), that sex education is the best way to educate adolescents on illicit sex and its consequences, but (65\%) feel shy to discuss about sex education and (37\%) still see sex education as a taboo, but (51\%) educate others positively about sex. These shows that adolescent develop a fair attitude towards sex education.

Research Question 3: What are the effects of sex education on adolescents?

Table XI: Showing the effect of sex education on adolescents

\begin{tabular}{|c|c|c|c|c|c|}
\hline $\mathrm{S} / \mathrm{N}$ & Statement & $\begin{array}{l}\text { Strongly } \\
\text { agree }(\%)\end{array}$ & $\begin{array}{l}\text { Agree } \\
(\%)\end{array}$ & $\begin{array}{l}\text { Disagree } \\
(\%)\end{array}$ & $\begin{array}{l}\text { Strongly } \\
\text { Disagree } \\
(\%)\end{array}$ \\
\hline 1 & Sex education has help reduce the rate of unwanted pregnancies & 10 & 32 & 43 & 5 \\
\hline 2 & $\begin{array}{l}\text { Sex education has help reduce the spread of sexually transmitted } \\
\text { disease }\end{array}$ & 15 & 31 & 40 & 4 \\
\hline 3 & Sex education encourages me to have sex & 25 & 13 & 22 & 40 \\
\hline 4 & $\begin{array}{l}\text { Adolescents are misled by sex education thereby encourages } \\
\text { dangerous sexual acts }\end{array}$ & 28 & 25 & 20 & 27 \\
\hline 5 & Sex education make one to be a responsible & 20 & 35 & 35 & 10 \\
\hline 6 & Sex education can change one's sexual attitude & 30 & 44 & 20 & 6 \\
\hline
\end{tabular}

According to the table (42\%) were of the opinion that sex education has helped reduce the rate of unwanted pregnancy; that sex education has helped reduce the spread of sexually transmitted diseases (46\%); but (38\%) are encouraged to have sex by sex education classes; that adolescents are misled by sex education thereby encouraging dangerous sexual acts (53\%); but sex education makes one to be responsible (55\%); and sex education can change one's sexual attitude (74\%). This shows that sex education is less effective on most of the adolescent. 
Research Question 4: What are the risks associated with sexual activities among adolescents?

Table XII. Showing the risk associated with sexual activities among adolescents

\begin{tabular}{|c|c|c|c|c|c|}
\hline $\mathrm{S} / \mathrm{N}$ & Statement & $\begin{array}{l}\text { Strongly } \\
\text { agree }(\%)\end{array}$ & Agree $(\%)$ & Disagree $(\%)$ & $\begin{array}{l}\text { Strongly } \\
\text { disagree }(\%)\end{array}$ \\
\hline 1 & Sexual activities in adolescents is addictive & 49 & 32 & 12 & 7 \\
\hline 2 & $\begin{array}{l}\text { Sexually transmitted diseases result from unprotected } \\
\text { sexual intercourse }\end{array}$ & 65 & 22 & 9 & 4 \\
\hline 3 & $\begin{array}{l}\text { Sexual activities in adolescent can lead to unplanned } \\
\text { pregnancy }\end{array}$ & 60 & 31 & 2 & 7 \\
\hline 4 & Abortion is dangerous & 74 & 21 & 3 & 2 \\
\hline 5 & Lack of proper sex education leads to rape & 46 & 21 & 3 & 2 \\
\hline 6 & $\begin{array}{l}\text { Improper sexual activities can give one a bad name and } \\
\text { causes social rejection }\end{array}$ & 64 & 22 & 6 & 8 \\
\hline
\end{tabular}

The above table expresses that ( $81 \%$ ) of the respondents are of opinion that sexual activities in adolescents is addictive; that sexually transmitted disease results from unprotected sexual intercourse (87\%); that sexual activities in adolescent can lead to unplanned pregnancy (91\%); that abortion is dangerous (95\%); that lack of proper sex education leads to rape (74\%); and that improper sexual activities can give one bad names and causes social rejection (86\%). This shows that adolescents are aware or the risks associated with illicit sexual activities.

\section{DISCUSSION}

Adolescence has been described as a period of storm and stress. It is a period characterized by the feeling and engaging in adult activities especially sexual activities which is contrary to the opinion of parents who still see them as children. Many studies have been conducted all over the world to study the level of knowledge and awareness of sex and sexuality among young adults.

The findings of this study show that majority of adolescents (74\%) are aware of sex education program but $26 \%$ claim they have never heard of it. Majority of adolescents got their first sex education from the media and friends, about $63 \%$ of males and $42 \%$ of females learned about sex and sexuality from their friends and $28 \%$ of males and $33 \%$ of females learned on sex and sexuality from the media, this in turn is higher than as few as 13\% of males and 33\% of females whom where thought by their parents. The study also shows that parents often give more sex information to females than males noted by the difference of $21 \%$, which is in concordance with the findings AHI (2008).

Most adolescents are exposed to sex information at an early age in life between the age of $5-15$ years as $25 \%$ of males and $18 \%$ of females were exposed around the age of 5 - 10years while $33 \%$ of males and $55 \%$ of females were exposed around 11 - 15 years which corresponds with the proposal of Aderele (2006) who claimed that sex information (positive or negative) is gotten by adolescents at a very young age this puts them at risk of developing harmful sexual behaviors early if not guided early in life. Milhausen and Herold (1999) also found gender difference in sexual behavior in their studies.

The results also entail that most of the adolescents think they are less or not informed on sex and sexuality as $20 \%$ and $28 \%$ of males and females respectively, thinks they are less informed, while $35 \%$ of males and $16 \%$ of males and females thinks they are not informed at all. 
A correlational study on the perception rating of adolescents on their level of sex awareness between public and private schools shows a strong negative correlation, with $38 \%$ and $34 \%$ of adolescents from public schools thought that they are less and not informed compared to only $15 \%$ and $12.5 \%$ from private schools that thought they were less or not informed. This shows that sex education in private schools is more effective than in public schools.

The results on table IX showed that $42 \%$ of adolescents lack knowledge about sex and sexuality though 58\% have fair or average knowledge on sex and sexuality.

Table X Showed that majority of the adolescents (65\%) have fair attitude towards sex education compared to $35 \%$ that have bad attitude towards sex education.

On Table XI It was shown that majority of the adolescents (54\%) agree that sex education has positive impact on them opposing $46 \%$ of them that think it doesn't.

Table XII showed that most adolescents (86\%) are aware of the risks associated with improper sexual activities compared to $14 \%$ that are not aware.

\section{IMPLICATION OF THE STUDY}

How amazing it is that parents and indeed the society educate their children about almost everything in life but feel hesitant about giving them sexual education. Sexuality is a natural in born phenomenon like eating food, and young children need to be given scientific, religious and factual knowledge to help them develop positive sexual attitude and responsible healthy behaviors to prevent teenage pregnancies, abortion, rape and sexually transmitted infections etc.

Sexual education forum (1999) posited that the educational implications of such ideas is that on the absence of adequate progressive sex education at all levels of child's developmental stage, children tend to invent their own mythologies about human sexuality which when reinforced by active social pressure (such as pornography, media, sexual magazines, and novels) their own natural sexual feelings plus their reproductive needs spells sexual health disastrous problems. All the stakeholders in the Nigerian education and health industries (parents, teachers, school nurses, and community health nurses) must help in conveying all necessary information needed by adolescents to them with every amount of seriousness.

\section{CONCLUSION}

As opined by peters (1999) education is designed to help and modify the culture (in relation to this research: modifies the culture of sexual risks and ignorance) the experience, skills and knowledge of a particular set of people from one generation to another as stated in the national policy of education section 1: subsection 5 namely the inculcation of the survival of the individual and the Nigerian society.

The findings of this research show that most of the adolescents have insufficient knowledge about sex education therefore adolescents require scientific, religious and factual information to help them develop positive sexual attitudes and responsible healthy behaviors

Moreover, most of the respondents agreed to the fact that sex education is effective, but most of them do not have sufficient knowledge so they require knowledge to prevent them from inventing their own mythologies and developing anti-social behaviors 
In most African homes, parents are not fully equipped to answer questions on sexual matters usefully. Even those who try to, passes faulty information to their children, the whole subject thus becomes surrounded by secrecy and the children becomes embarrassed to discuss these matters with their parents. Parents are in a better position to provide primary sexual information to their wards and adolescents should also make use the knowledge acquired positively.

Conclusively, sexuality education is imperative for homes and schools. The public is apparently ignorant of the sexual nature of human beings, having little or no knowledge of its biological and psychological significance in the living of a happy life. It is a well-known fact that the mysterious, create fear in words and fear thrives on ignorance. Ones the avenues of sexuality education have been established. It will go a long way to augment for the short falls of the education of sexuality provided by parents to children at home.

\section{RECOMMENDATIONS}

The study therefore recommends that:

$>$ Sex education should be part of school curriculum at all school levels (primary - tertiary)

$>$ Parents and guidance are the primary agents of socialization they should develop good communication skills with their children, and openly inform them

$>$ Abstinence plus education should be adopted at all levels of education

$>$ Universities and colleges of education should begin offering courses in sexology to produce specially trained teachers and social workers for public schools.

$>$ Restrictions or ban should be placed on the sales of pornographic material by law enforcement agencies.

$>$ Special web security and restrictions should be placed on pornographic websites

$>$ Parental control on internet use should be imposed by parents to their wards

$>$ Law enforcement agencies, religious bodies and parents should also teach and impose descents dressing and behaviors on youth to prevent rape, sexual molestation and harassment.

$>$ There is also need to include or allow young people or students themselves in developing and providing sex education as the practice serve as a means of ensuring the relevance and acceptability of what is provided

$>$ There is also need to consult young people of their needs at the point where programs are designed. 


\section{REFERNCES}

Adegoke, E. (2003). the role of the family in managing indiscipline among youths in Nigeria. Journal of counseling, (1) 45 - 51

Afifi, A., Trenholm, C., Devaney, B., Fortson, K., Quay, L., Wheeler, J., and clark, M. (2008). impact of four title V, abstinence education program. Final report Princeton, New Jersey

Ahamd, S. (2014). Masturbation. Retrieved from http://www.homeoint.org/site/ahmad/mastubation.htm

Akerele, A. (2004). Sexual risks and practices in Nigeria, muti - disciplinary approach to human kinetics and health education. Ibadan: Codat publication.

Akande, A.A. and Akande T.M. (2007). Knowledge and perception of sexuality education among students of rural secondary school in kwara state. University of Ilorin teaching hospital, Ilorin kwara state: Nigerian medical practitioner, 52 (3) 12-13.

Alford, S. (2008). Sex education programs, definitions and point by point comparison. Advocates for youth. Retrieved From: http://www.advocatesforyouth.org/publications-9-2/21655-sex-education-programs-definitions1and-point-by-point-comparison

Busari, A.O. (2006). Multi - disciplinary approach to human kinetics and health. Ibadan: Codat publication.

Collins, C., Summer, T., Alagiri, P., and Morin, S.F. (2009). Abstinence only VS Comprehensive sex education. Aids research institute: University of California, San Francisco

Duberstein, L.L., and Maddow, Z.I. (2012). Consequences of sex education on teen and young adult sexual behaviors and outcomes. Journal of adolescent health. The Guttmacher institute, New York. (51) 332 - 338

Esohe, K.P., and Peterinyang, M. (2015). Parents perception of teaching sexual education in secondary schools in Nigeria. International journal of innovative science, engineering and technology. 2(1)

Graber, O.F., and Brookes, D. (2002). Promoting reproductive health and reducing risk among adolescents, developmentally based interventions and strategies. New York

Idonije, B.O., Oluba, O.M., and Otamar, H.O. (2011). A study on knowledge, attitude and practice of contraception among secondary school students in Ekpoma, Nigeria. Journal of physics conference series. (2) 22-27

Ihajo, E.O., and Nase, B. (2015). Level of class, gender, type of secondary school, and Nigerian adolescent's sexual behaviour. British journal of psychology: United Kingdom. 3(1) 31

James, E., Rosen, J., Nancy, J.M. and Scott, M. (2004). Sexuality education in schools; the international experience and implications of Nigeria. Policy working paper series Number 12.

Kim, W., Kirby, D., Laris, B.A. and Rolleri, L. (2007). Impact of sex and HIV education program on sexual behaviors of youth in developing and developed countries: Youth research working paper No 7

Kirby, D. (2011). The impact of sex education on the sexual behavior of young people. United nations department of economics and social affairs: New York

Kulkarni, A. (2008). The association between sex education and youth's engagement in sexual intercourse and birth 
control use. Sex journal of adolescent health 42:89 - 96 Masturbation (n.d) in Wikipedia. Retrieved from http://en.m.wikipedia.org/masturbation

Mawlawi, F. and Subh, A. (2014). Sex education from an Islamic perspective. Retrieved 06/04/2015 from http://www.geocities.com/islamawareness/sex/perspective.html

Mechike, R.O. (2012). A literature review of causes, effect and remedies of teenage pregnancy, increase rate of sexually transmitted disease among adolescent Microsoft Encarta (computer software). (2009). Encarta dictionnaires, Microsoft corporation

Mueller, T.E. (2008) The association between sex education and youth's engagement in sexual intercourse, Age at first intercourse and birth control use at first sex. Journal of adolescent health. 42:89-96

Olabisi, S.O. (2010). Importance of impacting sex education on adolescent. University of agriculture: Abeokuta, Ogun state Nigeria Oxford, (2010). Oxford English mini dictionary ( $8^{\text {th }}$ ed) (mobile application software).

Spano, S. (2007). Stages of adolescent development: ACT for youth, center of excellence, University of Rochester: New York

Guidelines for Adolescents nutrition services. (2005). In J. Stang, and m. story. (Eds). Retrieved from http://www.epi.umm.edu/let/pubs/ado/books.htm

Ursula, C.E. and Nwobodo, A.N. (2010). Sexuality education practices among parents of students in Enugu education zone. Journal of research in education and society. 1(1)3-5

Wilson, L. (2014). Masturbation and its effects: The center for development. Retrieved 06/04/2015 from http://drwilson.com/Articles/Masturbation.htm

World health organization (2002). Lessons learned about life skill - based education preventing HIV/AIDs related discrimination 